\title{
The adsorptive removal of a cationic drug from aqueous solution using poly (methacrylic acid) hydrogels
}

\author{
SK Bajpai ${ }^{*}$, Navin Chand ${ }^{2}$ and Manika Mahendra' \\ 'Polymer Research Laboratory, Department of Chemistry, Govt.Model Science College, Jabalpur (M.P.), India \\ ${ }^{2}$ Scientist G\&Head Polymer Composites, Advanced Materials and Processes Research Institute, \\ (AMPRI) (Formerly RRL) (CSIR), Bhopal (M.P.)-462064, India
}

\begin{abstract}
This study describes adsorptive removal of the antibiotic drug ciprofloxacin hydrochloride from simulated water using poly(methacrylic acid) (PMAA) as adsorbent. The adsorbent was characterised by various instrumental techniques such as X-ray diffraction (XRD), differential scanning calorimetry (DSC), and Fourier transform infrared (FTIR) spectroscopy. The adsorption equilibrium data, as studied at 3 temperatures, namely, 15,25 and $37^{\circ} \mathrm{C}$, were best interpreted by the Langmuir adsorption isotherm model. Moreover, an increase in temperature reduces drug uptake. $\mathrm{A} \mathrm{pH}$ of the adsorption system in the range of 5.0 to 8.0 causes maximum adsorption of the drug. The presence of drug molecules in the adsorbent particles was shown by various techniques: X-ray diffraction (XRD), differential scanning calorimetry (DSC), Fourier transform infrared (FTIR) spectroscopy and scanning electron microscopy (SEM) analysis. Antibacterial studies also reveal the adsorption of the drug from solution.
\end{abstract}

Keywords: Adsorption, ciprofloxacin, Langmuir isotherm, X-ray diffraction, Fourier transform infrared (FTIR) spectroscopy

\section{INTRODUCTION}

Over the past 30 years, research has revealed pharmaceuticals and personal care products (PPCPs) to be emerging organic micro-contaminants due to their extensive use in human and veterinary medicine and their increasing occurrence in the aquatic environment (Avisar et al., 2010). The global market for pharmaceuticals has been estimated at between 100 000-200 $000 \mathrm{t} /$ year (Zuccato et al., 2010). PPCPs enter the environment at low concentrations, primarily as metabolites excreted by humans and animals or in effluents that are discharged into wastewater from hospitals, pharmacies, and chemical manufacturing facilities (Nikolaou et al., 2007). Once these compounds reach wastewater treatment plants (WWTPs), they are not completely removed and residual concentrations of these chemicals are frequently discharged in the treated effluent.

Fluoroquinolones (FQs) are a class of broad-spectrum antibiotics that are commonly used in both human and veterinary medicine. They inhibit key bacterial enzymes, such as DNA gyrase and topoisomerase IV, that are involved with unwinding the DNA helix for replication and transcription. FQs are of concern because they are widely used in Europe and the USA and are not readily biodegradable by microorganisms (Richards et al., 2004). They are not completely metabolised in the human body and approximately $20-90 \%$ of FQs ingested are excreted in their pharmacologically active forms, which leads to significant loads being discharged into domestic sewage (Paul et al., 2010). Furthermore, conventional wastewater treatment in WWTPs generally results in prolonged exposure of wastewaterborne bacteria to higher concentrations of FQs than are present in treated effluents because of the extended biomass solid

To whom all correspondence should be addressed

09993220651; e-mail: mnlbpi@rediffmail.com

Received 5 March 2013; accepted in revised form 4 December 2013. retention times at which secondary clarifiers usually operate. This is important because various FQs have been found in secondary wastewater effluents at concentrations close to minimal inhibitory concentrations (MICs) for various bacterial strains. Extended exposure of bacterial communities to MIC levels of FQs (and other antibacterial compounds) can result in an environment where the evolution of low-level antibacterial resistance is favoured in the affected bacterial communities. Ciprofloxacin (CPR), a second generation FQ and one of the most prescribed drugs in the world, has been widely researched because it has been regularly found in wastewater at MIC levels that could induce bacterial resistance. CPR is a broad-spectrum antibiotic that is effective against gram-positive and gramnegative bacteria. It was recommended during the anthrax outbreak in 2001 and has also been used to target biological agents of Legionnaire's disease and typhoid. It also belongs to a class of powerful FQs that have been linked to serious side effects which include ruptured tendons and neurological damage resulting from seizures (CBWInfo.com., 2005). Figure 1 shows the basic structure of CPR.

Many methods have been attempted, in the recent past, for the removal of antibiotic drugs from different water sources. These include coagulation and sedimentation (Boyd et al.,<smiles>O=CC1CC1n1cc(C(=O)O)c(=O)c2cc(F)c(N3CCNCC3)cc21</smiles>

Figure 1

Molecular structure of ciprofloxacin 
2003), biodegradation (Kimura et al., 2005), photo-transformation (Ereira et al., 2007), chlorination (Boyd et al., 2005), ozonation (Ernes et al., 2003), nanofiltration through membranes (Koyuncu et al., 2008), and adsorption (Caliskan and Gokturk, 2010; Marin and Beltran, 2010; Ghauch et al., 2009; Putra et al., 2009; Reverra et al., 2009; Zhang et al., 2012; Li et al., 2011 ). Out of these, adsorption processes have proved to be an effective technique because of major advantages, such as applicability over a large concentration range of sorbate, effective removal efficiency, low instrumentation cost, and the presence of many rate-controllable parameters (Carabineiro et al., 2011).

The present work describes removal of CPR by adsorption onto poly(methacrylic acid) (PMAA) using adsorption technique. The drug is cationic in nature and hence there is potential for its removal by PMAA, which contains ionisable-COOH groups, thus permitting their ionisation to yield free or exchangeable $\mathrm{H}^{+}$ions that can undergo ion-exchange processes with cationic $\mathrm{CPR}^{+}$ions present in the surrounding medium.

\section{EXPERIMENTAL}

\section{Materials}

The monomer methacrylic acid (MAc), crosslinker N,N'methylene bisacrylamide (MBAm), and initiator potassium persulphate (KPS) were obtained from High Media Chemicals, Mumbai, India and used as received. The drug ciprofloxacin (molecular formula $\mathrm{C}_{17} \mathrm{H}_{18} \mathrm{FN}_{3} \mathrm{O}_{3}$ ) was obtained from a local medical store. All chemicals used were analytical grade. Standard cultures of microorganisms were provided by the Department of Microbiology, Department of Bioscience, RDVV, Jabalpur (M.P., India). Nutrient broth and nutrient agars were obtained from Hi Media chemicals, India. Doubledistilled water was used throughout the investigation.

\section{Preparation of PMAA hydrogels}

The polymeric hydrogels were prepared as described in our previous study (Bajpai et al., 2011). In brief, $11.74 \mathrm{mM}$ of MAc, and $0.029 \mathrm{mM}$ of crosslinker MBAm, were dissolved in water to give a total volume of $5 \mathrm{~m} \ell$. To this, $0.023 \mathrm{mM}$ of initiator KPS was added and the resulting solution was transferred into a test tube (Borocil, id $2.5 \mathrm{~cm}$ ) and kept in an electric oven (Temp Star, India) at $60^{\circ} \mathrm{C}$ for a period of $2 \mathrm{~h}$. After the polymerisation was over, the test tube was broken, hydrogels were smashed, put in distilled water for a period of 3 days to remove unreacted salts and finally dried in a vacuum chamber at $40^{\circ} \mathrm{C}$ till they attained constant weight. The adsorption studies were carried out with fine particles obtained by passing the adsorbent particles through a standard sieve to obtain particles with mean geometrical diameter of $84 \mu \mathrm{m}$.

\section{Characterisation of adsorbent}

The FTIR spectrum of ordinary and drug-loaded samples was recorded on a Shimadzu, 8201 PC spectrophotometer using the $\mathrm{KBr}$ pelleting method. Thermal analysis was carried out using a thermo-gravimetric analyser (Mettler, Toledo, and GmbH. Switzerland). About $12 \mathrm{mg}$ of powdered sample was placed in a ceramic crucible and heated over a temperature range of 30 to $1000^{\circ} \mathrm{C}$ at a rate of $20^{\circ} \mathrm{C}$ per min under the flow of dry $\mathrm{N}_{2}$ at a flow rate of $30 \mathrm{ml} / \mathrm{min}$. XRD analysis of ordinary and drugloaded samples was performed with a Rikagu diffractometer (Cu radiation, $\lambda=0.1546 \mathrm{~nm}$ ) running at $40 \mathrm{kV}$ and $40 \mathrm{~mA}$.
The scanning rate was $2 \%$ in $2 \theta$ range of $30^{\circ}$ to $80^{\circ}$. The differential scanning colorimetery (DSC) analysis was performed using a Mettler Toledo Model DSC 822e instrument. The surface morphology of ordinary and drug-loaded samples was studied by scanning electron microscopy (SEM) using a Joel-Jsm-6390 LV scanning electron microscope. For SEM analysis, samples were mounted on an aluminium stub using an adhesive carbon tape and were coated with gold to a thickness of 200 Á.

\section{Drug adsorption studies}

A volume of $20 \mathrm{~m} \ell$ of drug solution, with concentration ranging from 10 to $50 \mathrm{mg} \cdot \ell^{-1}$, was placed in $125 \mathrm{~m} \ell$ Erlenmeyer flasks. A weighed amount of HG(29) particles was added to each solution and the flasks were shaken in a thermostatic shaker (Rivotek, India) at a constant speed of $100 \mathrm{r} / \mathrm{min}$ at a desired temperature. After shaking the flasks for $2 \mathrm{~h}$, the adsorbent particles were separated by centrifugation and the supernatant was analysed for the remaining drug concentration spectrophotometrically at wavelength $270 \mathrm{~nm}$. In preliminary experiments, it was observed that a time period of $2 \mathrm{~h}$ was sufficient for the attainment of equilibrium adsorption. The $\mathrm{pH}$ of the solutions was monitored during the course of experiments.

The amount of drug adsorbed onto adsorbent was calculated using the following expression:

$$
\mathrm{q}_{\mathrm{e}}=\frac{\left(\mathrm{C}_{0}-\mathrm{C}_{\mathrm{e}}\right)}{\mathrm{w}_{0}} \mathrm{x} \mathrm{v} \mathrm{mg} \cdot \mathrm{g}^{-1}
$$

where:

$q_{e}$ is the equilibrium adsorption capacity of CPR adsorbed on unit mass of adsorbent ( $\mathrm{mg} \cdot \mathrm{g}^{-1}$ )

$C_{o}$ and $C_{e}$ are the initial and the equilibrium drug concentrations $\left(\mathrm{mg} \cdot \ell^{-1}\right)$ respectively

$V$ is the volume of adsorbate solution $(\ell)$

$W$ is the amount of adsorbent $(\mathrm{g})$.

The per cent adsorption was calculated using the following expression:

$$
\text { Percent adsorption }=\frac{\left(\mathrm{C}_{0}-\mathrm{C}_{\mathrm{e}}\right) \times 100}{\mathrm{C}_{0}}
$$

All the experiments were carried out in triplicate and average values are reported in the results.

\section{Antimicrobial experimentation}

The antimicrobial action of drug CPR was investigated using the well method (Vimala et al., 2009) against the gram-negative bacteria E. coli. The principle of this method is fairly simple. When an antibiotic is placed inside the well of suitable nutrient agar medium previously inoculated with the test bacterium, the antibiotic diffuses radially outward through the agar, producing an antibiotic concentration gradient (Wang and Cai, 2008). The antibiotic is present at high concentration near the well and affects even minimally susceptible micro-organisms. As the distance from the well increases, the antibiotic concentration drops and only more susceptible pathogens are harmed. A clear zone or ring is present around an antibiotic well after incubation if the drug inhibits bacterial growth. The wider the zone surrounding a well, the more susceptible the pathogen is. The agar medium was sterilised in a conical flask at a pressure of $103 \mathrm{kPa}$ for $30 \mathrm{~min}$ and transferred onto sterilised Petri plates in a laminar air flow. After solidification of media, E. coli culture was spread on the solid surface of the media. 
Wells were then punctured and filled with $10 \mu \ell$ of CPR, after which the Petri plate was incubated for $24 \mathrm{~h}$ at $37^{\circ} \mathrm{C}$ in the incubation chamber. The antibacterial activity was assessed by measuring the diameter (in $\mathrm{mm}$ ) of the area around the well in which bacterial growth was inhibited.

\section{RESULTS AND DISCUSSION}

\section{Characterisation of PMAA hydrogel}

\section{FTIR spectral analysis}

Figure 2 shows the FTIR spectrum of PMAA hydrogel. The spectrum exhibits characteristic $\mathrm{C}=\mathrm{O}$ stretching at $1720 \mathrm{~cm}^{-1}$. The $-\mathrm{CH}_{2}$ deformation bending gives a band about $1477 \mathrm{~cm}^{-1}$ and $-\mathrm{OH}$ bonded groups give rise to a vibration band at about $2602 \mathrm{~cm}^{-1}$. In addition, a C-O stretching band representing carboxylic groups is observed at $1290 \mathrm{~cm}^{-1}$. Finally, a broad band in the region of $3400-3700 \mathrm{~cm}^{-1}$ is observed due to $-\mathrm{OH}$ stretching of carboxylic acid and $-\mathrm{NH}$ stretching from amide. Both peaks appear to have merged.

\section{Thermogravimetric analysis}

The thermogram of PMAA is shown in Fig. 3. The polymeric adsorbent shows fair thermal stability until about $180^{\circ} \mathrm{C}$; then in the temperature range of $180-260^{\circ} \mathrm{C}$ a weight loss corresponding to a first degradation process is observed. Above $260^{\circ} \mathrm{C}$ no relevant thermal event occurs until $300^{\circ} \mathrm{C}$, when a second weight loss, corresponding to the decomposition of the polymer starts. As reported by (McNeill et al., 1995) the first degradation process is related to the loss of water molecules through the formation of intra- and inter-molecular anhydride linkages and also to the de-carboxylation of a fraction of the $-\mathrm{COOH}$ groups by which $\mathrm{CO}_{2}$ is produced. In the second degradation stage, the polymer decomposes with the elimination of $\mathrm{CO}$ and $\mathrm{CO}_{2}$ by way of abundant backbone scission and formation of a small concentration of unsaturation. Similar results have also been reported elsewhere (Polacco et al., 2000).

\section{XRD analysis}

The X-ray analysis of ordinary PMAA adsorbent is shown in Fig. 4. It is clear from Fig. 4 that the diffractogram does not possess any sharp peaks throughout the range of $2 \theta$, thus suggesting that polymer does not have a crystalline nature, but is an amorphous solid. Indeed, most synthetic polymers have been reported to be amorphous in nature (Rawat et al., 2011).

\section{DSC analysis}

The DSC thermogram of ordinary PMAA hydrogel, as shown in Fig. 5, exhibits an endothermic peak at $102^{\circ} \mathrm{C}$, which may be designated as melting temperature $T_{m}$ of ordinary/unaltered polymer. The broader endothermic curve covers behaviour ranging from dehydration to temperature-dependent phase behaviour. The occurrence of the melting temperature indicates the melting of the crystalline phase of the cross-linked polymer (Ferreira et al., 2012). This crystalline nature arises due to cross-linking of polymeric chains by MB. The melting enthalpy $\left(\Delta H_{f}\right)$, the energy required to transform $1 \mathrm{~g}$ of a crystalline material to $1 \mathrm{~g}$ of an amorphous material, was calculated to be $106.93 \mathrm{~J} \cdot \mathrm{g}^{-1}$.
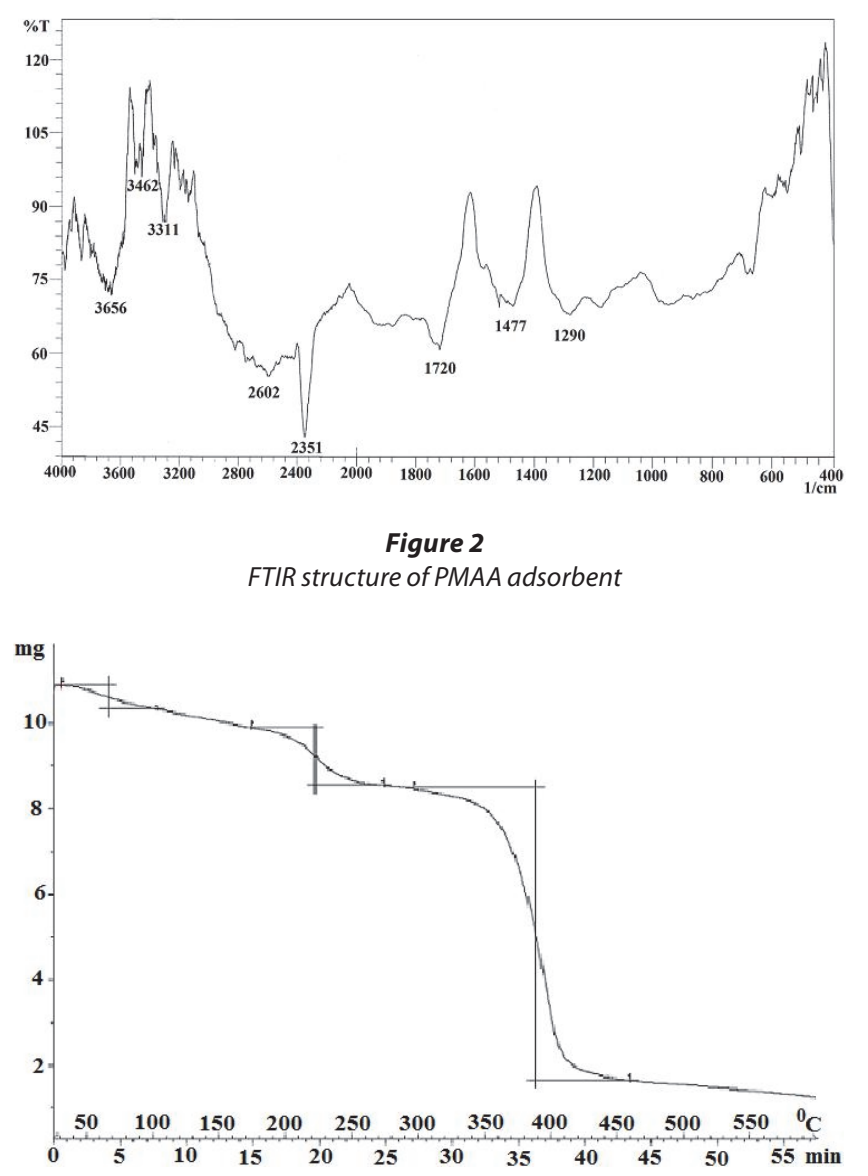

Figure 3

Thermogravimetric analysis of PMAA adsorbent

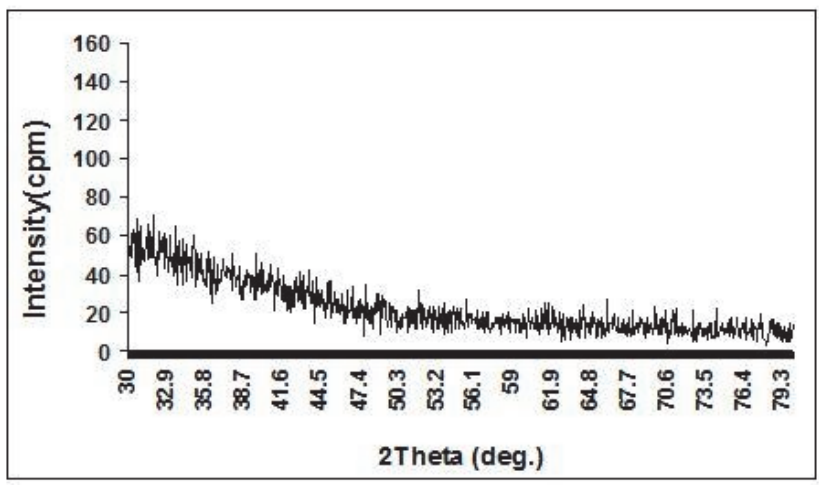

Figure 4

$X$-ray diffractogram of PMAA adsorbent

\section{Evidence in support of drug uptake}

The presence of drug molecules in the PMAA sorbent particles may be considered to be as a consequence of drug uptake by adsorbent particles. Therefore, the abovementioned analyses, namely, FTIR, XRD, DSC and SEM were also performed for the PMAA particles obtained after the adsorption process.

\section{FTIR spectral analysis of CPR-loaded adsorbent}

A close look at the FTIR spectrum of PMAA particles collected after the adsorption experiment (see Fig. 6) reveals the presence 

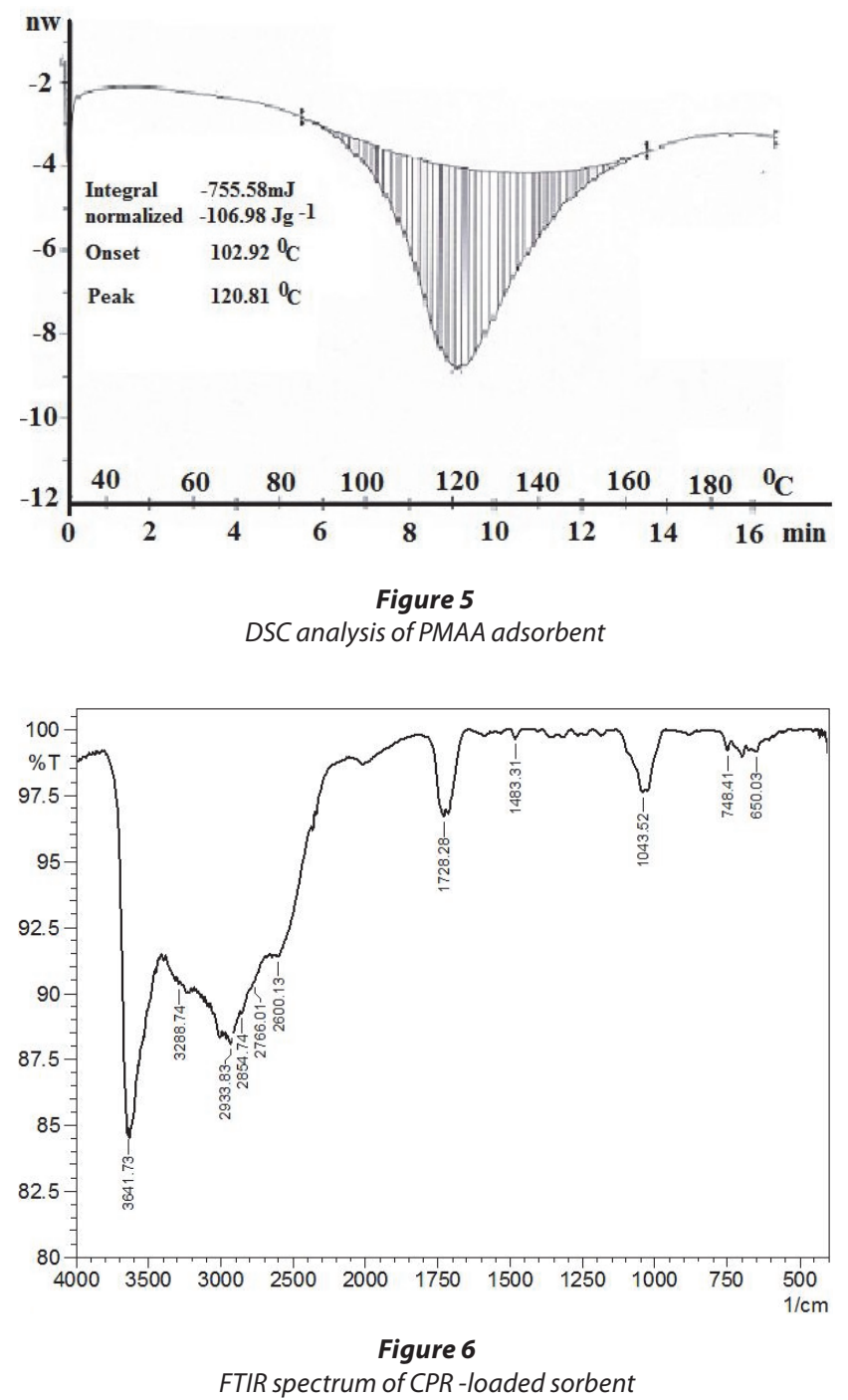

of a peak at $1043 \mathrm{~cm}^{-1}$ which may be assigned to the C-F stretching of the $\mathrm{CPR}$ molecule. The $\mathrm{C}-\mathrm{H}$ stretching vibrations of cyclopropyl group appear at $2933 \mathrm{~cm}^{-1}$. In addition, aromatic C-H bending and stretching appear at $748 \mathrm{~cm}^{-1}$ and $3030 \mathrm{~cm}^{-1}$, respectively. All the peaks mentioned above are absent in the FTIR of ordinary PMAA hydrogel particles (see Fig. 2). Therefore it may be inferred that after the adsorption experiment the CPR molecules are retained onto adsorbent particles.

It is also noteworthy that other peaks appearing in the above spectrum are also present in the FTIR of PMAA hydrogel particles as mentioned previously.

\section{XRD analysis of CPR-loaded sorbent}

The XRD pattern of drug-loaded PMAA, as shown in Fig. 7, which reveals 2 intense peaks at $2 \theta$ values of $17.6^{\circ}$ and $30.4^{\circ}$, which are fairly close to the XRD peaks obtained with pure ciprofloxacin, i.e., $19.1^{\circ}$ and $26.2^{\circ}$ (Sahooa et al., 2011). The presence of intense peaks in the XRD pattern of drug-loaded adsorbent confirms that ciprofloxacin molecules are retained on PMAA particles.

\section{DSC analysis of CPR-loaded adsorbent}

The DSC thermogram of ciprofloxacin-loaded PMAA is shown
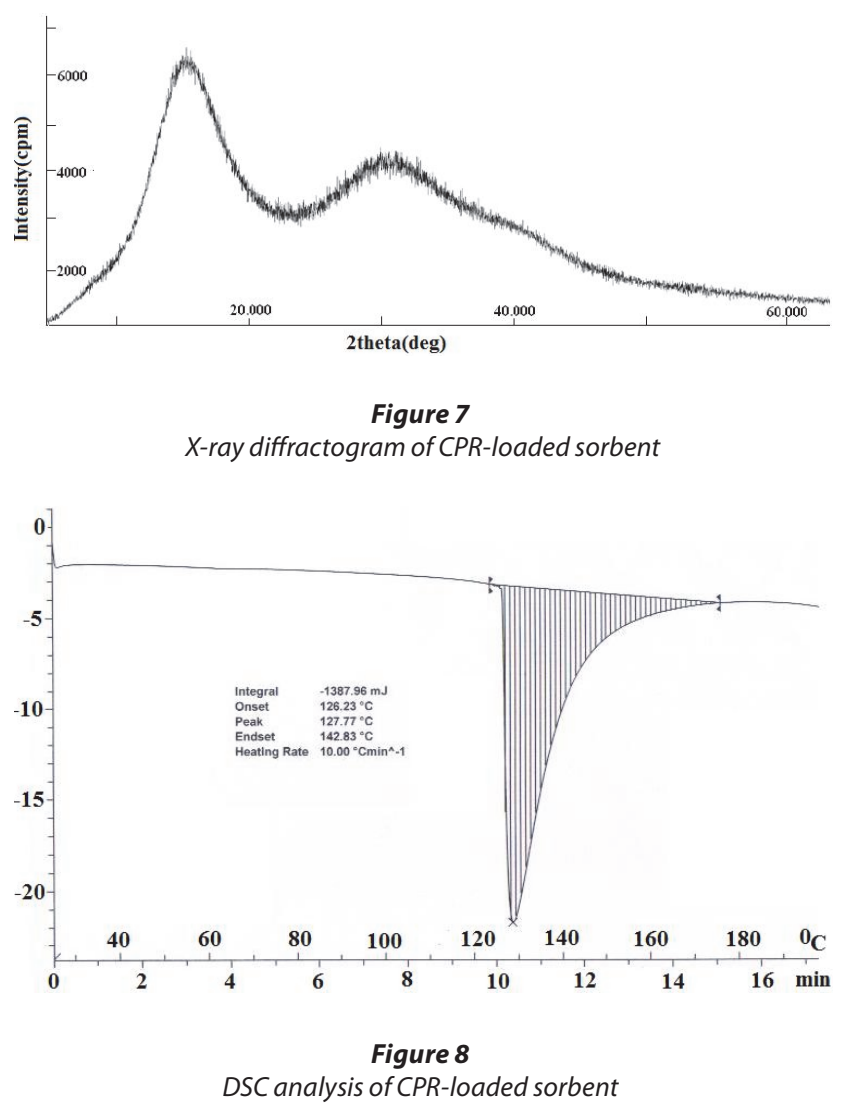

in Fig. 8. It is clear that the melting temperature is nearly $127.77^{\circ} \mathrm{C}$, thus suggesting an increase in the crystalline phase of polymer after the adsorption of CPR molecules. The observed increase in $T_{m}$ may be attributed to the increased crystallinity caused by binding of drug molecules to the active sites of the polymeric adsorbent. In addition, the enhanced sharpness as compared to the unaltered adsorbent also supports our argument that there is an increase in crystalline phase of the polymer. More heat is thus required to melt the polymeric segments of the crystalline phase.

\section{SEM imaging of CPR-loaded adsorbent}

The SEM image of sorbent particles after drug uptake is shown in Fig. 9. It can be seen that nanometer-sized drug molecules appear as white circles in the image, thus confirming the presence of drug molecules in the PMAA sorbent particles.

\section{Antibacterial study}

One of the main disadvantages of the presence of antibiotic drugs in water bodies is that they kill micro-organisms such as bacteria, fungi, and actinomycetes which take up heavy metal ions and thus help to protect the aquatic system. In this way, the presence of antibiotic drugs increases metal ion pollution by reducing the growth of micro-organisms.

To test this, $20 \mathrm{~m} \ell$ drug solution with concentration $30 \mathrm{mg} \cdot \ell^{-1}$ was agitated with $50 \mathrm{mg}$ of PMAA and the solution obtained after sorption was used to inhibit bacterial growth in Petri plates as described in the experimental section. The results, as illustrated in Fig. 10, indicate that after sorption the remaining solution is less effective in causing bacterial death, thus showing greater growth of bacterial colonies indicated by 


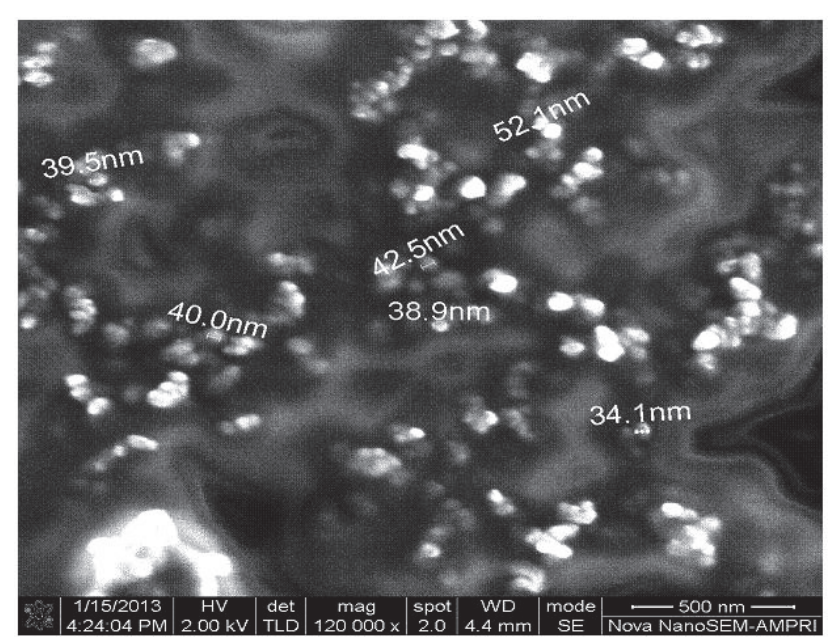

Figure 9

SEM image of CPR-loaded sorbent

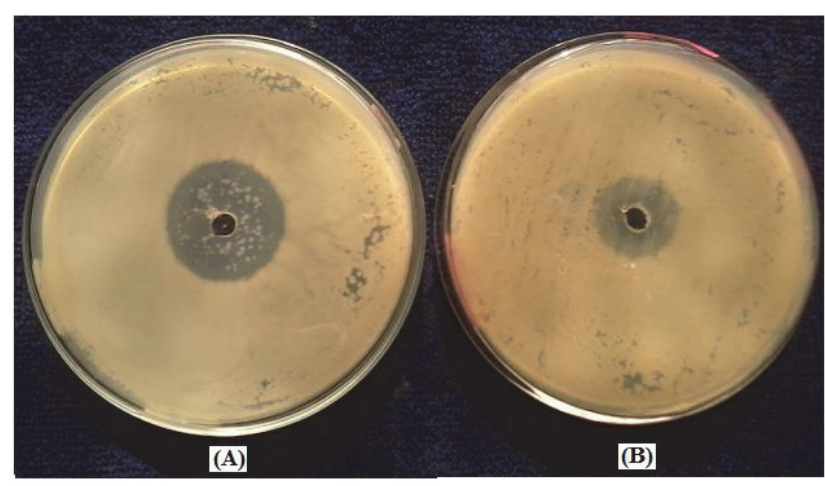

Figure 10

Zone of inhibition in Petri plate supplemented with drug solution (A) before adsorption and (B) after adsorption.

the relatively smaller radius of the zone of inhibition. Finally it can be concluded that higher growth of bacterial colonies in the Petri plate containing the post-adsorption drug solution is also evidence of drug uptake by the adsorbent.

\section{Effect of pH on drug uptake}

The results for the effect of $\mathrm{pH}$ on the amount of drug adsorbed $\left(\mathrm{mg}^{\mathrm{g}} \mathrm{g}^{-1}\right)$ are shown in Fig. 11. It can clearly be seen that adsorption is fairly low initially, at low $\mathrm{pH}$ values of the solution. As the $\mathrm{pH}$ increases, the extent of adsorption also increases and attains an optimum value of nearly $8.1 \mathrm{mg} \cdot \mathrm{g}^{-1}$ when $\mathrm{pH}$ of the solution reaches 5.0. Beyond $\mathrm{pH} 5.0$ the degree of adsorption remains almost constant till $\mathrm{pH} 9.2$ is reached. Therefore it can be inferred that optimum drug uptake is obtained in the $\mathrm{pH}$ range of 5 to 9 . In order to explain the observed findings it is essential to know the charge profiles of both adsorbent and adsorbate.

The $\mathrm{pH}$ of the sorbent/sorbate adsorption system plays a significant role in governing the amount of sorbate available. This parameter becomes especially important when sorbent or sorbate both carry groups which may be protonated/ deprotonated with change in $\mathrm{pH}$ of the sorption system. The $\mathrm{pK}_{\mathrm{a} 1}$ and $\mathrm{pK}_{\mathrm{a} 2}$ values of CPR are 5.5 and 7.7, respectively (Zhang and Huang, 2007). The cationic form, $\mathrm{CH}^{+}$, exists due

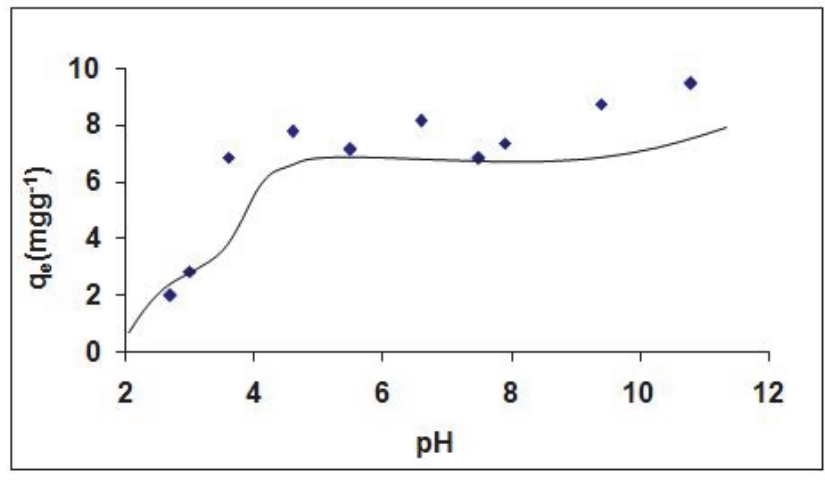

Figure 11

Effect of $\mathrm{pH}$ on drug uptake

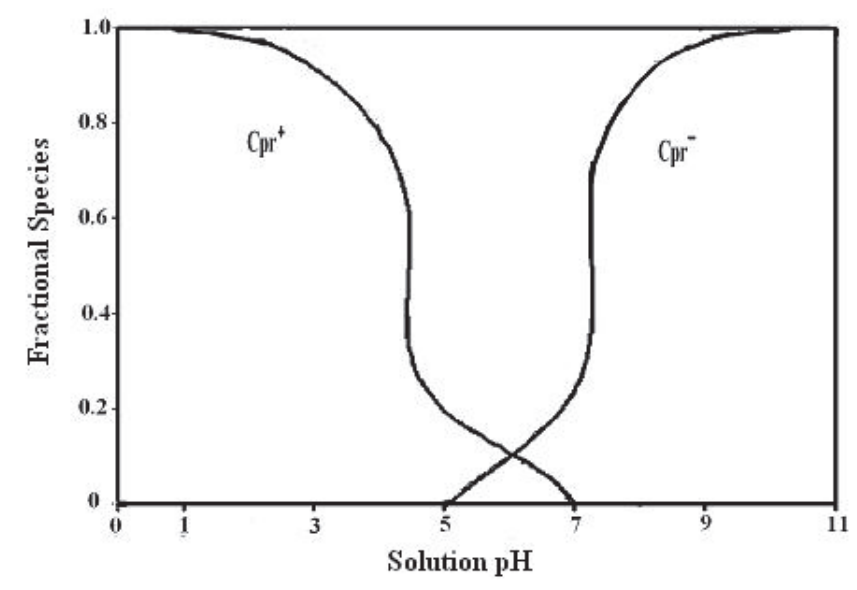

Figure 12

Speciation of CPR under different $p H$ conditions

to protonation of the amine group in the piperazine moiety (Fig. 12) when solution $\mathrm{pH}$ is below 6.1. When solution $\mathrm{pH}$ is above 8.7, the anionic form, CPR-, prevails, due to ionisation of carboxylic groups. When solution $\mathrm{pH}$ is between 5.5 and 7.7 the zwitter ionic form, $\mathrm{CPR}$, is the dominant species, which results from the charge balance between the above two groups (see Fig. 12). Moreover, the adsorbent PMAA has ionisable $-\mathrm{COOH}$ groups which are ionised when $\mathrm{pH}$ of the solution exceeds 5.0.

In the light of the above facts, a plausible explanation is as follows: Initially when $\mathrm{pH}$ of the solution is low, e.g. 3.0, the adsorbent PMAA remains un-ionised and drug molecules carry positive charges due to protonation of the amine group in the piperazine moiety as stated above (see Fig. 12). Therefore there are no binding forces available for adsorption of CPR to occur onto adsorbent particles. However as the $\mathrm{pH}$ of the solution exceeds 4.0 , the $-\mathrm{COOH}$ groups of PMAA adsorbent begin to ionise to render negative charges on the adsorbent molecules due to the presence of - $\mathrm{COO}^{-}$groups. At this $\mathrm{pH}$, about $60 \%$ of drug molecules are also carrying positive charges and therefore there is an appreciable degree of adsorption observed. As the $\mathrm{pH}$ value reaches 5.0, the $\mathrm{COO}$ - groups are ionised to a great extent thus imparting negative charges on the adsorbent particles, while at this $\mathrm{pH}$ nearly $80 \%$ of drug molecules are zwitter-ionic. Now there are chances of favourable adsorption due to interaction between negatively-charged adsorbent particles and the positive ends 


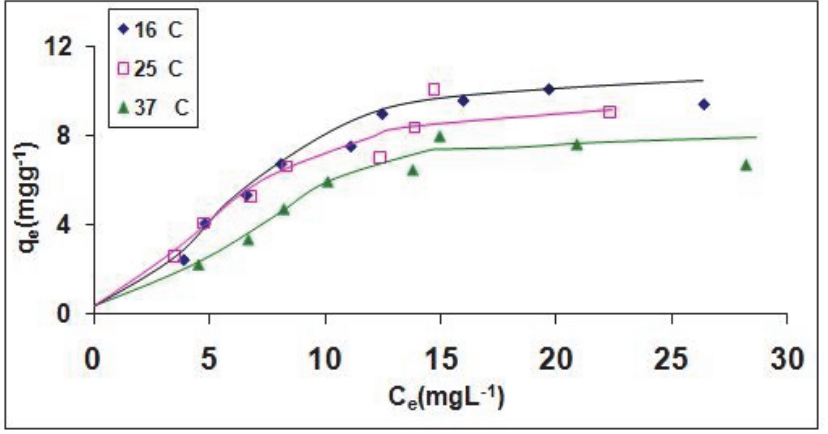

Figure 13

Equilibrium drug uptake, $q_{e}$ as a function of equilibrium concentration $C_{e}$ for drug adsorption onto PMAA

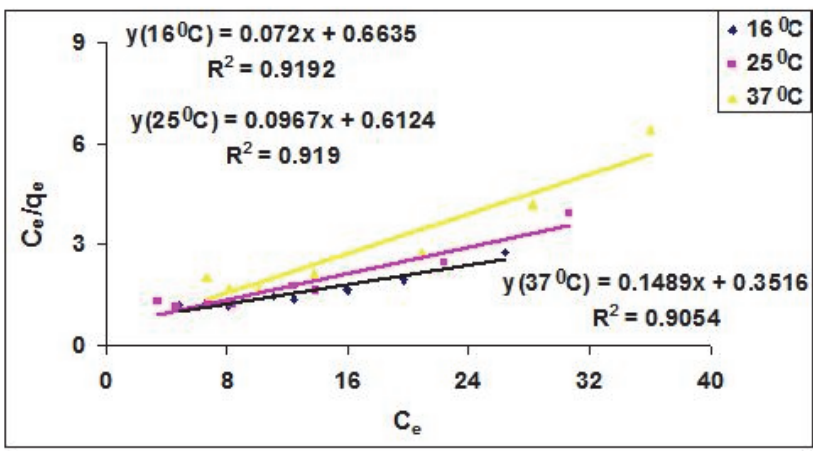

Figure 14

Langmuir plot for drug uptake of PMAA hydrogel adsorbent at $25^{\circ} \mathrm{C}$

of drug molecules. This situation continues till the $\mathrm{pH}$ of the solution reaches 7.7. As the $\mathrm{pH}$ is increased further, the fully ionised carboxylic groups render excessive negative charges to adsorbent particles while the drug molecules have a predominance of negative charges; under this situation it is expected that adsorption will not be favoured. However the results obtained indicated almost optimal adsorption. This could be attributable to $\mathrm{H}$-bonding interactions between the $\mathrm{H}$ atom of the amine group in the piperazine moiety and the $\mathrm{O}$ atom from - $\mathrm{COO}^{-}$groups. There is one more possible reason for higher drug uptake in this $\mathrm{pH}$ region - the fully swollen hydrogel may permit drug molecules to enter into the swollen network (Bajpai et al., 2011).

\section{Equilibrium drug adsorption study}

The adsorption equilibrium isotherm is usually expressed by relating an amount of adsorbate adsorbed per unit mass of sorbent $q_{e}\left(\mathrm{mg}^{-1} \mathrm{~g}^{-1}\right)$ to the equilibrium concentration of sorbate solution, $C_{e}\left(\mathrm{mg} \cdot \ell^{-1}\right)$, at a fixed temperature. The Langmuir equation is perhaps the most widely used adsorption isotherm model, due to its simplicity and strong theoretical basis. Three essential premises of the Langmuir isotherm are monolayer coverage, adsorption site equivalence and independence (Sohn and Kim, 2005). The $C_{e}$ versus $q_{e}$ profiles for drug uptake at 3 different temperatures, namely, 16,25 and $37^{\circ} \mathrm{C}$, are shown in Fig. 13. It is clear that $q_{e}$ increases with $C_{e}$ and finally attains saturation, thus showing a typical isotherm.

The analysis of the equilibrium uptake data using various isotherm models is an important step to establish a model that can be successfully used for design purposes (Chi et al., 2010).
Out of various isotherm models, the Langmuir, Freundlich and Temkin models are the most frequently used. The various constants involved in these isotherm models provide useful information to predict sorption capacities (Baek et al., 2010). The Langmuir isotherm model (Langmuir, 1918) is given as:

$$
\mathrm{C}_{\mathrm{e}} / \mathrm{q}_{\mathrm{e}}=1 / \mathrm{Q}_{0} \mathrm{~K}_{\mathrm{L}}+\mathrm{C}_{\mathrm{e}} / \mathrm{Q}_{0}
$$

where:

$q_{e}\left(\mathrm{mg} \cdot \mathrm{g}^{-1}\right)$ is the amount of drug adsorbed onto PMMA at equilibrium

$C_{e}$ is the equilibrium concentration $\left(\mathrm{mg} \cdot \ell^{-1}\right)$

$K_{L}\left(\ell \cdot \mathrm{mg}^{-1}\right)$ is the Langmuir constant related to the energy of adsorption

$Q_{o}\left(\mathrm{mg} \cdot \mathrm{g}^{-1}\right)$ is the adsorption capacity corresponding to complete monolayer coverage.

Using the equilibrium drug uptake data, obtained at 16,25 and $37^{\circ} \mathrm{C}$, linear plots were obtained between $C_{e}$ and $C_{e} / q_{e}$, as shown in Fig. 14, which exhibited good $R^{2}$ values.

The equilibrium drug uptake data were also studied using the Freundlich adsorption isotherm model (Freundlich, 1906), which can be expressed as:

$$
q_{e}=K_{F} \cdot C_{e}^{1 / n}
$$

where:

$K_{F}$ and $n$ are Freundlich constants which exhibit their usual meaning.

The Temkin isotherm model, developed by Temkin and Pyzhev (1940), is expressed as Eq. (5):

$$
\mathrm{q}_{\mathrm{e}}=\frac{\mathrm{RT}}{\mathrm{B}_{\mathrm{T}}} \ln \mathrm{A}_{\mathrm{T}}+\frac{\mathrm{RT}}{\mathrm{B}_{\mathrm{T}}} \ln \mathrm{C}_{\mathrm{e}}
$$

Here, $B_{T}$ is constant related to heat of sorption and $A_{T}$ is Temkin isotherm constant.

The parameters obtained from Langmuir, Freundlich and Temkin equations are shown in Table 1.

A close look at the regression values obtained indicates that Langmuir and Freundlich models are almost equally applicable while the Temkin model is a poorer fit. The maximum monolayer adsorption capacities $\mathrm{Q}_{0}$ obtained from Langmuir model are $13.888,10.341$ and $6.715 \mathrm{mg}^{-1} \mathrm{~g}^{-1}$ at 16,25 and $37^{\circ} \mathrm{C}$ respectively. These values indicate that there is an appreciable adsorption of drug CPR onto PMAA. It is also clear that there is negative temperature dependency of degree of adsorption, i.e., adsorption decreases with an increase in temperature. This may be attributed to the fact that as the temperature increases, the kinetic energy of drug molecules is enhanced and this weakens the attractive forces between the drug molecules and the binding sites available on the sorbent particles. Although there is normally positive temperature dependence observed in most adsorption studies, this is usually attributed to the enhanced pore diffusion of the sorbate molecules into porous adsorbents. The opposite finding in the present case leads to an inference that PMAA adsorbent is non-porous in nature.

\section{Effect of temperature on CPR uptake}

In order to estimate the standard free energy change $\Delta \mathrm{G}^{\circ}$, the Langmuir constant $K_{L}$ was used in the following equation:

$$
\Delta \mathrm{G}^{0}=-\mathrm{RT} \ln \mathrm{K}_{\mathrm{L}}
$$




\begin{tabular}{|c|c|c|c|c|c|c|c|c|c|}
\hline \multicolumn{10}{|c|}{$\begin{array}{c}\text { TABLE } 1 \\
\text { Parameters of Langmuir, Freundlich and Temkin equations }\end{array}$} \\
\hline \multirow{2}{*}{$\begin{array}{c}\text { Temp. } \\
\left({ }^{\circ} \mathrm{C}\right)\end{array}$} & \multicolumn{3}{|c|}{ Langmuir } & \multicolumn{3}{|c|}{ Freundlich } & \multicolumn{3}{|c|}{ Temkin } \\
\hline & $Q_{0}$ & $K_{L}$ & $R^{2}$ & $K_{F}$ & $n$ & $R^{2}$ & $A_{T}$ & $\boldsymbol{b}_{T}$ & $R^{2}$ \\
\hline & $\left(\mathrm{mg} \cdot \mathrm{g}^{-1}\right)$ & $\left(\ell \cdot \mathrm{mg}^{-1}\right)$ & & $\left(\mathrm{mg} \cdot \mathrm{g}^{-1}\left(\mathrm{l} \cdot \mathrm{mg}^{-1}\right)^{1 / \mathrm{n}}\right)$ & & & $\left(\ell \cdot \mathrm{mol}^{-1}\right)$ & & \\
\hline 16 & 13.888 & 0.108 & 0.919 & 1.029 & 1.218 & 0.913 & 56.486 & 595.49 & 0.915 \\
\hline 25 & 10.341 & 0.157 & 0.982 & 1.353 & 1.466 & 0.8982 & 18.539 & 848.512 & 0.7394 \\
\hline 37 & 6.715 & 0.423 & 0.905 & 1.046 & 1.521 & 0.7734 & 16.683 & 915.768 & 0.8434 \\
\hline
\end{tabular}

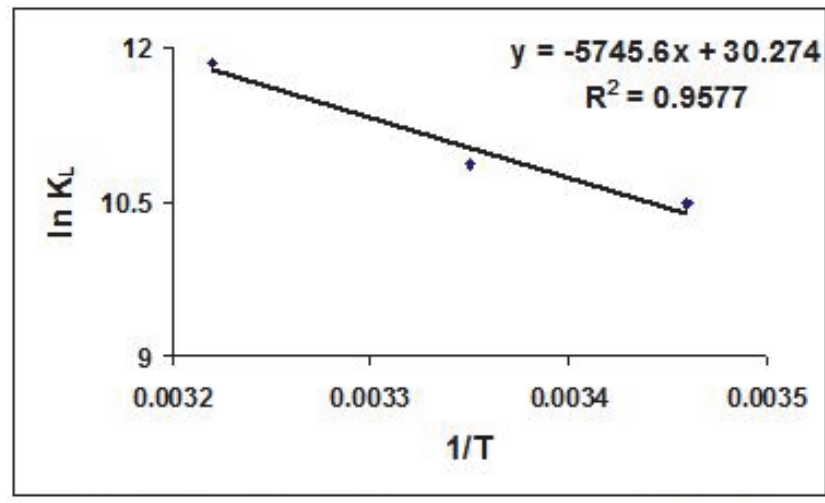

Figure 15

The plot of In $K_{L}$ versus $1 / T$ for the evaluation of standard enthalpy and entropy change

where:

$T$ is the absolute temperature $(\mathrm{K})$

$\mathrm{R}$ is gas constant $\left(8.314 \mathrm{~J} \cdot \mathrm{mol}^{-1} \mathrm{~K}\right)$

The standard enthalpy change $\left(\Delta H^{\circ}\right)$ and entropy change $\left(\Delta S^{\circ}\right)$ were calculated using the slope and intercept of Van't Hoff plot of $\ln K_{L}$ versus 1/T (see Fig. 17) as per the following relationship:

$$
\ln \left(\mathrm{K}_{\mathrm{L}}\right)=\frac{\Delta \mathrm{S}^{0}}{\mathrm{R}}-\frac{\Delta \mathrm{H}^{0}}{\mathrm{RT}}
$$

The values of $\Delta G^{o}, \Delta H^{o}$ and $\Delta S^{o}$ are given in the Table 2.

\begin{tabular}{|c|c|c|c|}
\hline \multicolumn{4}{|c|}{ TABLE 2 } \\
Evaluation of thermodynamic parameters \\
\hline Temperature & $\Delta \mathbf{G}^{\circ}\left(\mathbf{k J} \cdot \mathrm{mol}^{-1}\right)$ & $\Delta \mathrm{H}^{\circ}\left(\mathbf{k J} \cdot \mathrm{mol}^{-1}\right)$ & $\Delta \mathrm{S}^{\circ}\left(\mathrm{J} \cdot \mathrm{mol}^{-1} \mathrm{~K}^{-1}\right)$ \\
\hline $16^{\circ} \mathrm{C}$ & -25.192 & & \\
\cline { 1 - 2 } $25^{\circ} \mathrm{C}$ & -26.903 & \multirow{2}{*}{170.212} & \multirow{2}{*}{670.623} \\
\cline { 1 - 2 } $37^{\circ} \mathrm{C}$ & -39.425 & & \\
\hline
\end{tabular}

\section{CONCLUSION}

From the above study it may be concluded that the PMAA sorbent appears to be quite effective in removing antibiotic drug ciprofloxacin from simulated wastewater. The maximum sorption capacity $Q_{0}$ decreases with increase in the solution temperature, thus the adsorption process is exothermic in nature. The changes observed in XRD, DSC and FTIR of drug-loaded PMAA sorbent confirm the uptake process. The uptake is best interpreted in terms of the Langmuir isotherm model.

\section{REFERENCES}

AVISAR D, LESTER Y and MAMANE H (2010) pH induced polychromatic UV treatment for the removal of a mixture of SMX, OTC and
CIP from water. J. Hazardous Mater. 175 (1-3) 1068-1074.

BAEK MI-HWA, IJABBEMI CO, SE-JIN O and KIM DONG-SU (2010) Removal of malachite green from aqueous solution using degreased coffee bean. J. Hazardous Mater. 176 820-828.

BAJPAI SK, CHAND N and MAHENDRA M (2011) The adsorptive removal of cationic dye from aqueous solution using Poly (methacrylic acid) Hydrogels: Part I. Equilibrium studies. Int. J. Environ. Sci. 2 (3) 1609-1624.

BOYD GR, REEMTSMA H, GRIMM DA and MITRA S CAN (2003) Pharmaceuticals and personal care products (PPCPs) in surface and treated waters of Louisiana, USA and Ontario, Canada. Sci. Total Environ. 311 (1-3) 135-149.

BOYD GR, ZHANG S and GRIMM DA (2005) Naproxen removal from water by chlorination and biofilm processes. Water Res. 39 (4) 668-676.

CALISKAN E and GOKTURK S (2010) Adsorption characteristics of sulfamethoxazole and metronidazole on activated carbon. Sep. Sci. Technol. 45 (2) 244-255.

CARABINEIRO SA, THAVORN-AMORNSRI T, PEREIRA MF and FIGUEIREDO JL (2011) Adsorption of ciprofloxacin on surfacemodified carbon materials. Water Res. 45 (15) 4583-4591.

CBWInfo.com (2005) Ciprofloxacin. URL: http://www.cbwinfo.com/ Pharmaceuticals/Cipro.html (Accessed 27 March 2011).

CHI Z, LIU R and ZHANG H (2010) Potential enzyme toxicity of oxytetracycline to catalase. Sci. Total Environ. 408 (22) 5399-5404

ERNES TA, STUBER J, HERRAMANN N, McDOWEL LD, RIED A, KAMPMANN M and TEISER B (2003) Ozonation: a tool for removal of pharmaceuticals, contrast media and musk fragrances from wastewater? Water Res. 37 (8) 1976-1982.

EREIRA VJ, LINDANE KG and WEINBERG HS (2007) Evaluation of UV irradiation for photolytic and oxidative degradation of pharmaceutical compounds in water. Water Res. 41 (19) 4413-4423.

FERREIRA L, VIDAL MM and GIL MH (2001) Design of a drugdelivery system based on polyacrylamide hydrogels. Evaluation of structural properties. Chem. Educ. 6 (2) 100-103.

FREUNDLICH H (1906) Adsorption in solutions. Phys. Chem. Soc. 40 1361-1368.

GHAUCH A, TUQAN A and ABOU ASSI H (2009) Antibiotic removal from water: elimination of amoxicillin and ampicillin by microscale and nanoscale iron particles. Environ. Pollut. 157 (5) 1626-1635.

KIMURA K, HARA H and WATANABE Y (2005) Removal of pharmaceutical compounds by submerged membrane bioreactors (MBRs). Desalination 178 135-140.

KOYUNCU OA, ARIKAN MR, WIESNER and RICE C (2008) Removal of hormones and antibiotics by nanofiltration membranes. J. Memb. Sci. 309 94-101.

LANGMUIR I (1918) The adsorption of gases on plane surfaces of glass, mica and platinum. J. Am. Chem. Soc. 40 1361-1403.

LI Z, HONG H, LIAO L, ACKLEY CJ, SCHULZ LA, MACDONALD RA, MIHELICH AL and EMARD SM (2011) A mechanistic study of ciprofloxacin removal by kaolinite. Colloids Surf. B Biointerfaces 88 (1) 339-344.

MARIN FJ and BELTRAN DE HEREDIA J (2010) On the use of carbon blacks as potential low-cost adsorbents for the removal of nonsteroidal anti-inflammatory drugs from river water. J. Hazardous Mater. 177 (1-3) 1046-1053.

McNEILL IC, AHMED S and MEMETEA L (1995) Thermal degradation of vinyl acetate-methacrylic acid copolymer and 
homopolymers. I. A FTIR spectroscopic investigation of structural changes in the degrading material. Polym. Degrad. Stabil. 47 (3) 423-433.

NIKOLAOU A, MERIC S and FATTA D (2007) Occurrence patterns of pharmaceuticals in water and wastewater environments. Anal. Bioanal. Chem. 387 (4) 1225-1234.

PAUL T, DODD MC and STRATHMANN TJ (2010) Photolytic and photocatalytic decomposition of aqueous ciprofloxacin: transformation products and residual antibacterial activity. Water Res. 44 (10) 3121-3132

POLACCO G, CASCONE MG, PETERCA L and PERETTI A (2000) Thermal behaviour of poly(methacrylic acid)/poly( $N$-vinyl-2pyrrolidone) complexes. Eur. Polym. J. 36 2541-2544.

PUTRA EK, PRANOWO R, SUNARSO J, INDRASWATI N and ISMADJI S (2009) Performance of activated carbon and bentonite for adsorption of amoxicillin from wastewater: mechanisms, isotherms and kinetics. Water Res. 43 (9) 2419-2430.

RAWAT A, MAHAVAR HK, CHAUHAN S, TANWAR A and SINGH PJ (2012) Optical band gap of polyvinylpyrrolidone/polyacrilamide blend thin films. Ind. J. Pure Appl. Phys. 50 100-104.

REVERRA-UTRILLA J, PRADOS-JOYA G, SANCHEZ-POLO M, FERRO-GARCIA MA and BAUTISTA-TOLEDO I (2009) Removal of nitroimidazole antibiotics from aqueous solution by adsorption/ bioadsorption on activated carbon. J. Hazardous Mater. 170 (1) 298-305.

RICHARDS SM, WILSON CJ, JOHNSON DJ, CASTLE DM, LAM M, MABURY SA, SIBLEY PK and SOLOMON KR (2004) Effects of pharmaceutical mixtures in aquatic microcosms. Environ. Toxicol. Chem. 23 (4) 1035-1042.

SAHOOA S, CHAKRABORTI CK, MISHRA SC, NANDA UN and NAIKA S (2011) FTIR and XRD investigations of some fluoroquinolones. Int. J. Pharmacy Pharm. Sci. 3 (3) 165-170.

SOHN S and KIM D (2005) Modification of Langmuir isotherm in solution systems - definition and utilization of concentration dependent factor. Chemosphere 58 115-123.

TEMKIN MJ and PYZHEV V (1940) Kinetics of ammonia synthesis on promoted iron catalysts. Acta Physicochim. U.R.S.S. 12 217-222.

VIMALA V, SIVADU KS, MOHAN YM, SREEDHAR B and RAJU KM (2009) Controlled silver nanoparticles synthesis in semihydrogel networks of poly(acrylamide) and carbohydrates: A rational methodology for antibacterial application. Carbohydrate Polym. 75 463-471.

WANG J and CAI Z (2008) Incorporation of the antibacterial agent, miconazole nitrate into a cellulosic fabric grafted with $\beta$-cyclodextrin. Carbohydrate Polym. 72 695-700.

ZHANG H and HUANG CH (2007) Adsorption and oxidation of fluoroquinolone antibacterial agents and structurally related amines with goethite. Chemosphere 66 1502-1512.

ZHANG X, GAO X, HUO P and YAN Y (2012) Selective adsorption of micro ciprofloxacin by molecularly imprinted functionalized polymers appended onto ZnS. Environ. Technol. 33 (16-18) 2019-2025.

ZUCCATO E, CASTIGLIONI S, BAGNATI R, MELIS $M$ and FANELLI $R$ (2010) Source, occurrence and fate of antibiotics in the Italian aquatic environment. J. Hazardous Mater. 179 (1-3) 1042-1048. 